nology is most advanced, at present exceeds five million. To find work for people is now a major domestic political problem. But science still advances. It is estimated that when automation and other improvements foreshadowed are applied, one man will be able to produce as much as four or five at present.

Equally great is the advance in biological science. Where modern medicine has been applied, the expectation of life at birth has increased by twenty years since 1900. It is now being applied in all countries and in forty years the present population of the world is likely to be doubled, and doubled again in the succeeding thirty years. Yet medical research is being intensified - and rightly so. But too little thought is being given to how long the Earth will be able to support its human inhabitants.

Thus, in one generation, the advance of science has made war obsolete unless, of course, our civilization lacks the intelligence to avoid committing suicide. It has lifted the burden of labour from man's shoulders and changed scarcity, with inevitable poverty, for the majority of the people in the world to one of potential abundance for all mankind. It has made it possible to free the human family from most of the suffering and premature death which has afflicted it since man first appeared on the Earth.

What is needed to-day is, not more science, but changes in the structure of society to enable people to enjoy the rich fruits science has already made available. Governments-even to some extent, totalitarian governments-cannot bring about big changes until people realize the need for them. The British Association, especially by its presidential addresses, is doing much to enlighten the public on the powers of science and the problems they have created. It is suggested that this should now be its main function.

Several sections might consider common big issues and report their findings in non-technical language. Section $\mathrm{X}$, which consists of about 170 allied societies the members of which represent the more intelligent part of the population of Britain, might consider the changes needed to adjust society to the new atomic age. By doing this it would promote knowledge, wisdom and benevolence, or in other words 'culture', which this scientific age so sadly lacks.

The British Association can perform an even more valuable ervice than it has done in the past by adapting its meetings to throw the searchlight of science on world affairs.

\title{
THE GLASGOW REGION
}

\section{The Glasgow Region}

A General Survey. Edited by Prof. Ronald Miller and Dr. Joy Tivy. Pp. xix $+325+20$ plates. (Glasgow: Local Committee of the British Association for the Advancement of Science, 1958.)

WHILE it can scarcely be said that the various W centres visited by the British Association vie with one another in the production of a handbook to the neighbourhood, the local committees have certainly succeeded in producing a valuable series of books, impressive both in quality and in size. The handbook for the Glasgow meeting is no exception. It is a very substantial volume, well supplied with plates and other illustrations, and embellished with the University and City arms on the covers.

The volume has been prepared under the editorship of Prof. Ronald Miller. and Dr. Joy Tivy, of the Department of Geography in the University of Glasgow, who emphasize in the foreword that it has to serve a double purpose : it must introduce the region to the visitor and it must give the local reader food for thought, thus providing for both divisions of the British Association membership. This they have succeeded in doing, mainly by means of a series of chapters surveying different aspects of the scene.

Prof. Miller opens with a chapter on the geography of the region. This is followed, quite naturally, by a résumé of the geology by Prof. T. Neville George. C. A. Halstead deals with the climatology. The chapter on land utilization is divided into three parts, written by Prof. John Walton (vegetation), Prof. Donald S. Hendrie (agriculture) and J. E. James (forestry) respectively. Biology of the Clyde and its associated waters is dealt with by Dr. W. D. Russell Hunter, who also provides some notes on the land animals of the area. The Clyde in prehistory and in the Roman period is discussed by Dr. Horace Fairhurst and Dr. Anne S. Robertson respectively. Chapters on Glasgow itself and its history to 1750 (Prof. George S. Pryde) and the industrial and commercial developments (John B. S. Gilfillan and H. A. Moisley) bring the story to 1914. There follow chapters on the engineering industries (Drs. James Orr and Sarah C. Orr), fuel and power (Dr. R. Common on coal and gas, and D. R. Diamond on electricity and petroleum) and the economy of Glasgow (Prof. Alec Cairncross). Human problems are the subject of chapters on population distribution (Dr. Joy Tivy), the Glasgow overspill problem (Berenice D. Baker), transport (John F. Sleeman) and Glasgow's spheres of influence as a regional capital (H. A. Moisley). The histories of the University of Glasgow and of the Royal College of Science and Technology are briefly summarized by Prof. John D. Mackie and Charles G. Wood respectively, A. McLaren Young surveys the fine arts and Catherine B. Smith provides brief notes on research institutions in the area.

"The Glasgow Region" is a worthy addition to the series of handbooks prepared by the enthusiastic and hard-worked local committees in the cities visited by the British Association. For the teacher of geography they are veritable mines of information, up to date and authoritative, for regional studies; for the visiting member of the British Association they are equally useful for reference purposes, and also as reminders of many interesting and valuable occasions. There is no index. 